\title{
A Modified Novel Approach to Control of Thyristor Controlled Series Capacitor Based on direct Power Theory
}

\author{
V.N.Ganesh ${ }^{1}$, Dr.C.Sharmeela ${ }^{2}$, Dr.Chandan Madzundar ${ }^{3}$ \\ ${ }^{1}$ Research Scholar, Allahabad University \\ ${ }^{2}$ EEE Dept, Anna University, \\ ${ }^{3}$ ECE Dept, Allahabad University,
}

\begin{abstract}
The paper presents the development of a PQ theory based on control system for the Thyristor Controlled Series Capacitor (TCSC). In distribution networks for active filter control instantaneous PQ theory has been successfully used. In this scheme, system response is very fast to reduce the response time, which allows instantaneous control in the line power flow. Using ATP-EMTP simulated results were obtained for different operating conditions.
\end{abstract}

Key words: - FACTS, EPS, Instantaneous Power, PQ Theory, TCSC, TCR, ATP-EMTP.

\section{Introduction}

The concept of alternating current transmission systems incorporating power electronic-based and other static controllers to enhance controllability and increase power transfer capability are known as FACTS. The idea has had some success in certain areas such as VAR dispatch and control. However, the full use of FACTS for power flow control has had limited application in part due to reliability concerns, and in part due to availability of components and cost of these devices.

The potential ability to control the flow of electric power path, and the ability to effectively join electric power networks that are not well interconnected, suggests that FACTS may find new applications as electric utilities merge and as the sale of bulk power between distant exchange partners become more common. The improvement of the transient response of a system with FACTS devices is a very important consideration.

FACTS technology, which allows flexibility of the system operation from basically any point of view: series and parallel reactive compensation, active and reactive power flow control, static and dynamic voltage control, etc. The TCSC consists of a series compensating capacitor shunted by a thyristor controlled reactor (TCR) placed in series with the transmission line. So its operation allows controlling the rate of rise or reducing the series impedance of transmission lines within certain values. This feature is more advantages compare to conventional methods for compensation, where it allows only reduction of series impedances of transmission lines. There are various control schemes for the TCSC depending on the function it must fulfill in the EPS: for example, controlling the current value, damping power oscillations, maintaining the power flow constant along the transmission line.

Controlling parameters of EPS in dynamic operation requires a extreme reduction of calculation times in order to assurance the efficiency of the scheme used. For this reason the PQ theory looks like an effective and accurate tool in the calculation of the necessary variables to found the required control. Until now, this theory has been successfully used by four-wire EPS and active filters, but until now there have not been any reports of control applications on transmission systems. Due to the reasons explained above in this paper some of the merits that this theory could bring to the control schemes of the TCSC are presented. In the following section the theory of instantaneous power will be briefly explained, followed by the control scheme to be implemented and its inclusion in the TCSC model developed for the EMTP-ATP. Finally the results and conclusions are presented.

\section{Instantaneous Power Theory}

The theory of instantaneous power allows the calculation of the average power / phase, in an easy and exact way, from the measurement of instantaneous currents and voltages. The equations proposed by Nabae and Akagi in order to transform the variables of instantaneous voltage and current values, without the use of Fourier series i.e., in time domain. The spatial vectors are the following:

$$
\left[\begin{array}{l}
i_{\alpha} \\
i_{\beta}
\end{array}\right]=\sqrt{\frac{2}{3}} \cdot\left[\begin{array}{rrr}
1 & -\frac{1}{2} & -\frac{1}{2} \\
0 & \frac{\sqrt{3}}{2} & -\frac{\sqrt{3}}{2}
\end{array}\right] \cdot\left[\begin{array}{l}
i_{a} \\
i_{b} \\
i_{c}
\end{array}\right]
$$




$$
\left[\begin{array}{l}
e_{\alpha} \\
e_{\beta}
\end{array}\right]=\sqrt{\frac{2}{3}} \cdot\left[\begin{array}{ccc}
1 & -\frac{1}{2} & -\frac{1}{2} \\
0 & \frac{\sqrt{3}}{2} & -\frac{\sqrt{3}}{2}
\end{array}\right] \cdot\left[\begin{array}{l}
v_{a} \\
v_{b} \\
v_{c}
\end{array}\right]
$$

In this case $i_{a}, i_{b} \& i_{c}$ are the instantaneous currents that circulating through the line where the TCSC is installed. Similarly, $\mathrm{V}_{\mathrm{a}}, \mathrm{V}_{\mathrm{b}} \& \mathrm{~V}_{\mathrm{c}}$ are instantaneous line-to-ground voltages measured at the sending-end of the transmission line. The following transformation allows the calculation of the average active power and the maximum value of the reactive power of the system in an instantaneous way:

$$
\begin{aligned}
& p=e_{\alpha} i_{\alpha}+e_{\beta} i_{\beta}=v_{a} i_{a}+v_{b} i_{b}+v_{c} i_{c}=\frac{d W}{d t} \\
& q=e_{\alpha} i_{\beta}-e_{\beta} i_{\alpha}=\frac{1}{\sqrt{3}}\left[i_{a}\left(v_{c}-v_{b}\right)+i_{b}\left(v_{a}-v_{c}\right)+i_{c}\left(v_{b}-v_{a}\right)\right]
\end{aligned}
$$

From these power components the current components in the $\alpha-\beta$ coordinates can be calculated

$$
\left[\begin{array}{c}
i_{\alpha} \\
i_{\beta}
\end{array}\right]=\left[\begin{array}{cc}
e_{\alpha} & e_{\beta} \\
-e_{\beta} & e_{\alpha}
\end{array}\right]^{-1} \cdot\left[\begin{array}{l}
p \\
q
\end{array}\right]=\frac{1}{e_{\alpha}^{2}+e_{\beta}^{2}}\left[\begin{array}{cc}
e_{\alpha} & -e_{\beta} \\
e_{\beta} & e_{\alpha}
\end{array}\right] \cdot\left[\begin{array}{l}
p \\
q
\end{array}\right]
$$

In the scheme shown in below, there are three stages that can be identified: measurement and conditioning, control, and thyristor pulse generating unit.

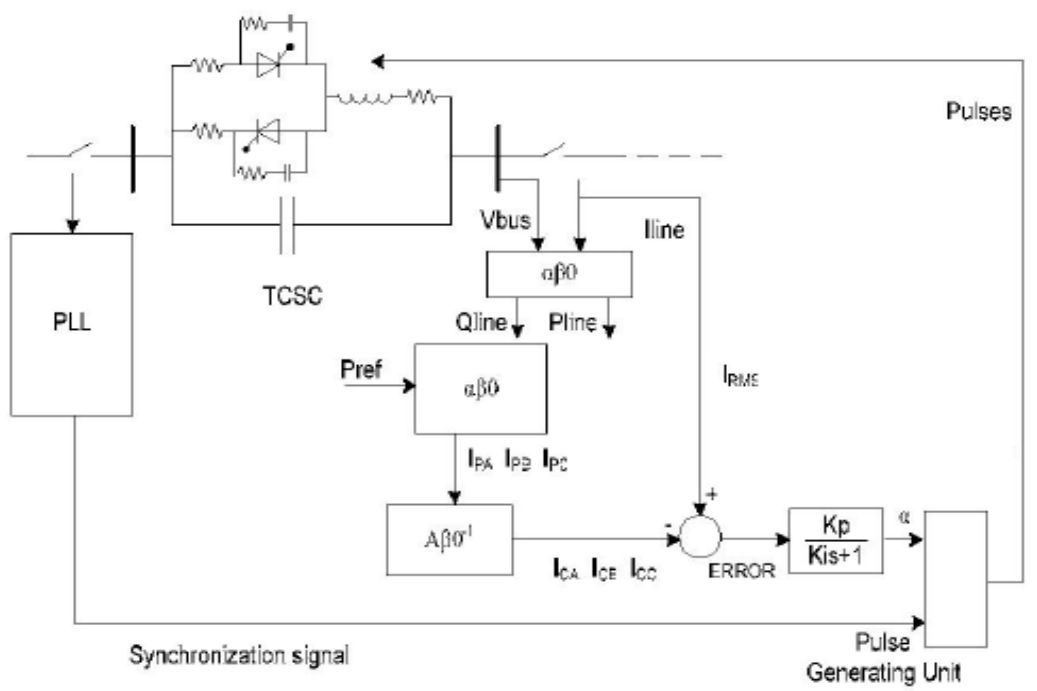

\subsection{Measurement and conditioning.}

The main objective of this stage is the measurement of the $V_{a}, V_{b} \& V_{c}$ at the sending end of the transmission line $\left(\mathrm{V}_{\text {bus }}\right)$ where the TCSC is located and also the instantaneous values of line currents $\mathrm{i}_{\mathrm{a}}, \mathrm{i}_{\mathrm{b}}$ and $\mathrm{i}_{\mathrm{c}}$ $\left(\mathrm{I}_{\text {line }}\right)$. With those signals, the calculation of $\mathrm{P}$ and $\mathrm{Q}\left(\mathrm{P}_{\text {line }}, \mathrm{Q}_{\text {line }}\right)$ that circulate through the line is made by $(1),(2)$, (3)

\subsection{Control System}

With the values of currents necessary to force the desired value of $\mathrm{P}$ along the line $\left(\mathrm{P}_{\mathrm{ref}}\right)$, the thyristor angle is calculated in order to obtain the requested operating condition. This is achieved through the comparison of the current that circulates along the line $\left(\mathrm{I}_{\text {line }}\right)$ with the desired currents obtained from (1) \& (5). At this point two different cases were chosen in order to obtain information about the sensitivity and flexibility of the control scheme: comparison of effective (RMS) and instantaneous current values. In the first case the effective value of the circulating currents are calculated and compared with the RMS currents obtained by (1) \& (5), while in the second the same operation is made but using the instantaneous values. This comparison produces a signal called ERROR that forces a change of the angle $(\alpha)$ by the PI controller shown in figure 1. 
The PLL (Phase Looked Loop) proposed in [6] was used to achieve this objective, and is shown in figure 2.

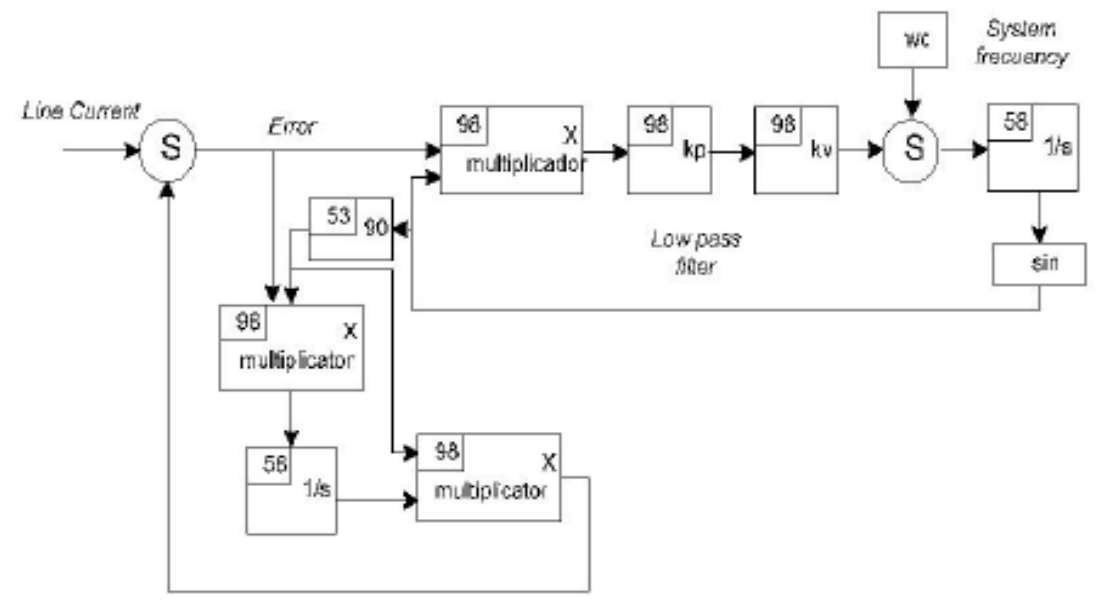

The PLL obtains the fundamental component of the line current, which will be used to firing the thyristors.

\section{Simulations}

The simplified 230-kV power system used to prove the proposed control scheme is illustrated in figure 4. It consists of a transmission line compensated by a TCSC between two equivalent systems and was modeled in the ATP-EMTP program.

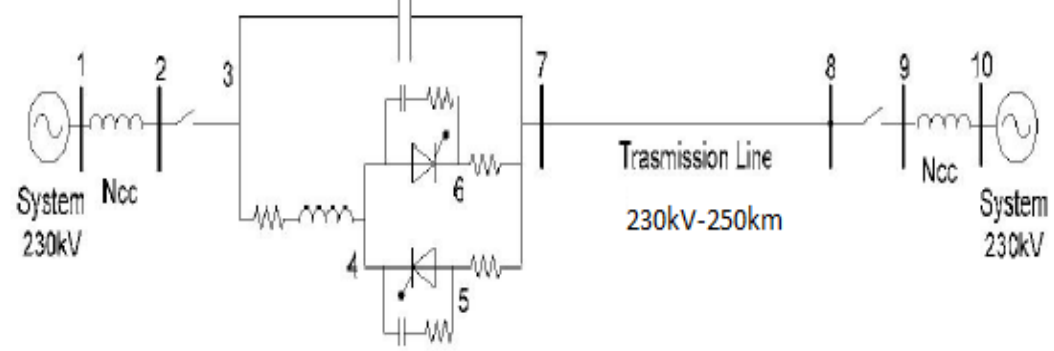

SNUBBER

\subsection{System data}

Table I indicates the values used for the simulation of the power system shown in the above figure

\begin{tabular}{|l|l|}
\multicolumn{2}{c|}{ Table I System Data } \\
\hline Transmission Line & Ro $=0.3979 \Omega / \mathrm{km}$ \\
& $\mathrm{R}+=0.0800 \Omega / \mathrm{km}$ \\
& $\mathrm{L}=4.3799 \mathrm{mH} / \mathrm{km}$ \\
& $\mathrm{L}+=1.3299 \mathrm{mH} / \mathrm{km}$ \\
& Co $=6.2210 \mathrm{nF} / \mathrm{km}$ \\
& $\mathrm{C}+=8.8210 \mathrm{nF} / \mathrm{km}$ \\
& Length $=255 \mathrm{~km}$ \\
\hline TCSC & $\mathrm{L}=13.31 \mathrm{mH}$ \\
& $\mathrm{R}=\mathrm{IOm} \Omega$ \\
& $\mathrm{C}=88.44 \mu \mathrm{F}$ \\
& $\mathrm{R}_{\text {snubber }}=2 \mathrm{k} \Omega$ \\
& $\mathrm{C}_{\text {snubber }}=0.1 \mu \mathrm{F}$ \\
& $\mathrm{R}_{\text {thyristor }}=1 \mathrm{~m} \Omega$ \\
& \\
\hline Equivalent systems & Scc3f $1=\mathrm{Scc} 3 \mathrm{f} 21000 \mathrm{MVA}$ \\
& Xo/X $\pm=1$ \\
& $\mathrm{~V} 2=1.00 \mathrm{pu}$ \\
& $\delta=20^{\circ}$ \\
\hline
\end{tabular}


The TCSC can change the impedance value between $-30 \Omega$ and $-50 \Omega$ in a continuous way (capacitive mode). This range will be obtained by firing the TCR within $150^{\circ}-180^{\circ}$. The resonance point is around $140^{\circ}$ as shown in figure 5.

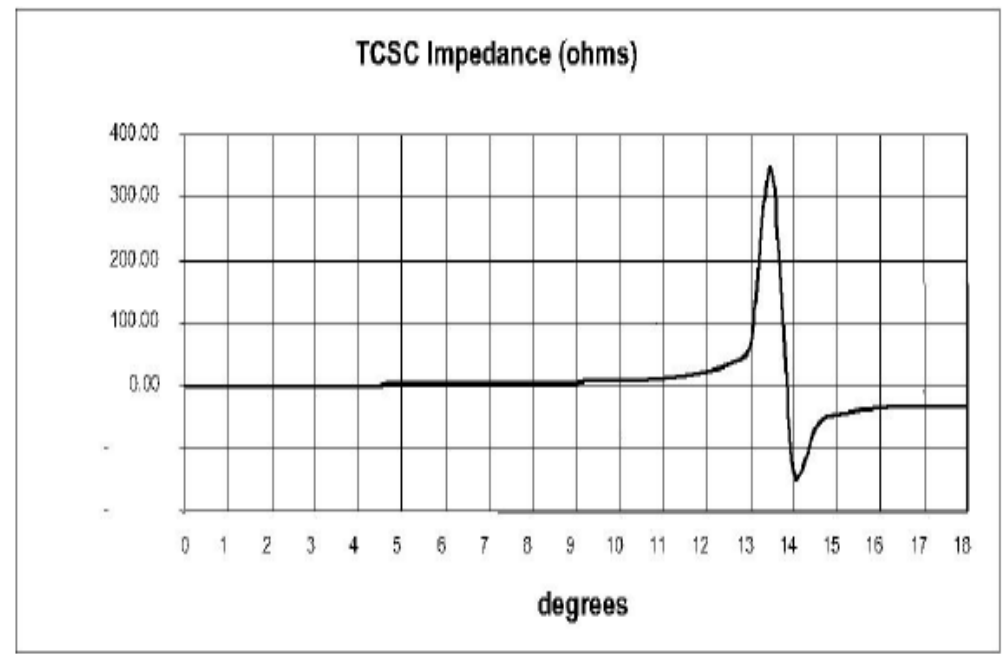

In order to test the performance of the proposed control scheme with the two variants, two cases were simulated: the first one explores the reaction of the TCSC's control system to disturbances, and the second one observes the versatility of the control scheme to change the operating conditions of the transmission line.

Case 1

\section{Simulations Results}

To keep the active power flow through the transmission line constant after disturbances was the goal of this case. Figure 6 shows the power behavior on the transmission line if there is no control over the TCSC. It can be seen that the power goes from $117 \mathrm{Mw}$ to $133 \mathrm{Mw}$ at $0.3 \mathrm{~s}$.

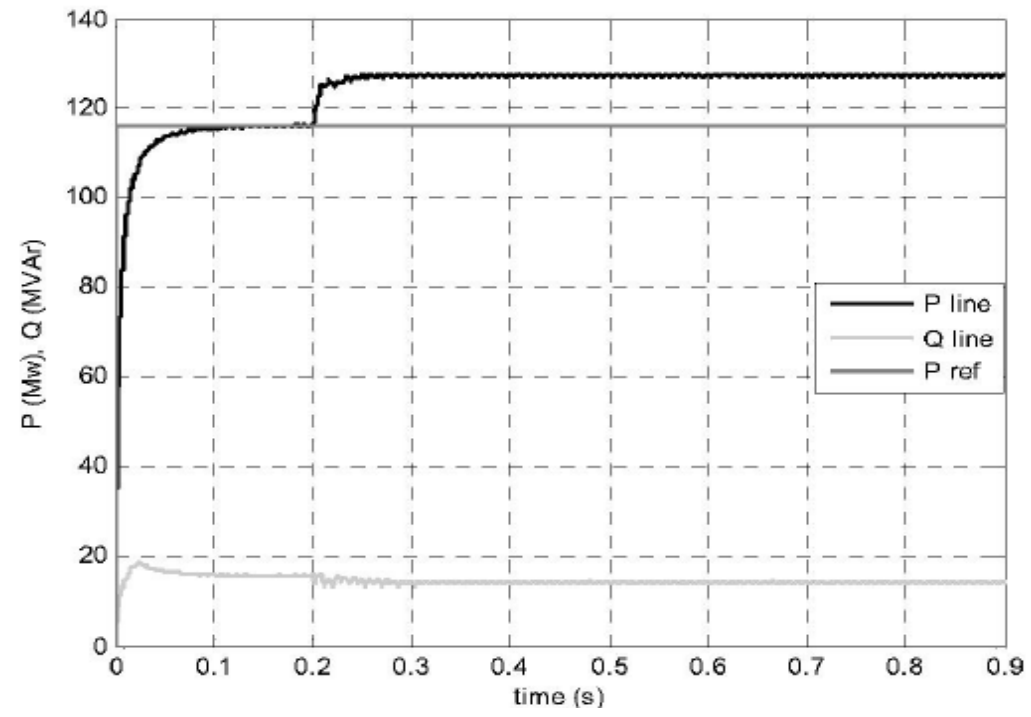

Results of simulated variants for the control system are shown in figures 7 and 8 . In the first one it can be seen the response of the control system using the effective values (schema 1), while the second was made using instantaneous values (schema 2). 


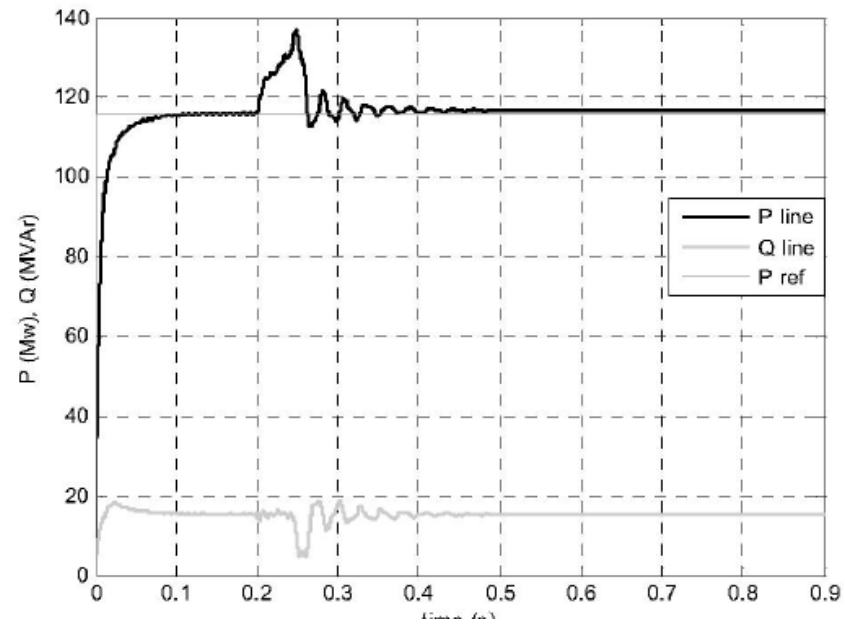

The simulated behavior of the proposed control shows better performance when the instantaneous currents are used as control variable. In figure 8 the first spike is $3.1 \%$ lower than with scheme 1: besides, it stabilizes in $0.4 \mathrm{~s}$ while the RMS system does it in $0.46 \mathrm{~s}$.

In the case of reactive power, although both cases have the same constant value, the scheme based on instantaneous values presents a better dynamic behavior.

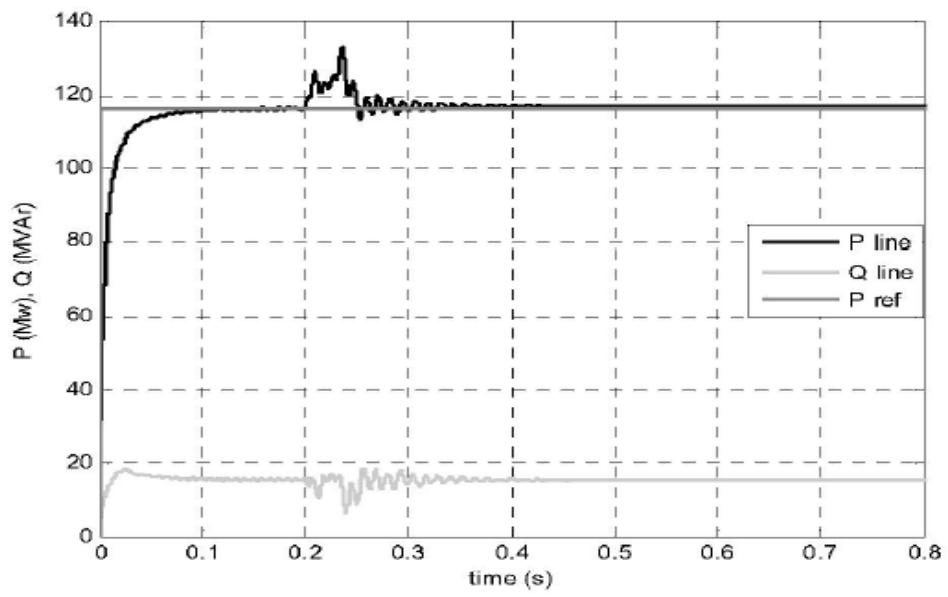

Case 2

To test the power flow control on the transmission line was the objective in this case. Starting with 120 $\mathrm{Mw}$ of power flow through the line, steps of $10 \%$ and $20 \%$ were simulated at $0.6 \mathrm{~s}$ (raise) and $0.95 \mathrm{~s}$ (decrease). The reference power was raised to $133 \mathrm{Mw}$ and later on it was reduced to $106 \mathrm{Mw}$.

Results obtained with both control schemes are shown in figures 9 and 10.

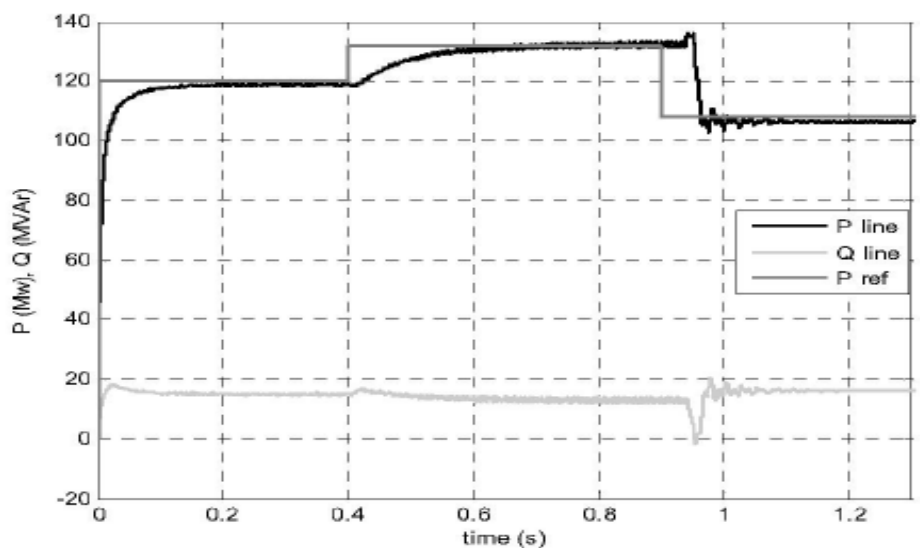

As seen in figures 9 and 10, the schema 1 based on RMS values takes longer response times than schema 2. Therefore the tendency for a better dynamic response given for the instantaneous values was verified. 
The reactive power behavior on all of the cases presents small variations, as predicted with the adjustment of the control scheme used.

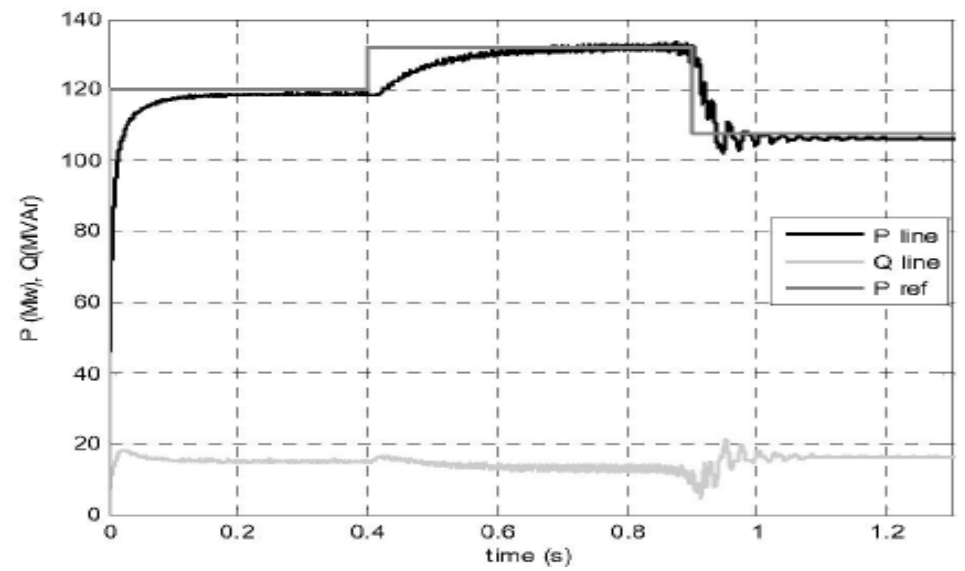

\section{Conclusions}

From the implemented tests, it can be concluded that the installation of TCSCs in transmission lines offers controlling the power flow in an efficient manner. For achieving fast system response to reduce the response time instantaneous power theory has been used. Using instantaneous values of current to drive the control system implemented on the TCSC could bring additional results however, a further stability study under disturbances should be done in order to guarantee the system robustness.

\section{References}

[1] N. Noroozian, M. Ghandari, "Improving Power System Dynamics By Series Connected FACTS Devices", IEEE Trans. Power Delivery, vol.12, N' 4, pp. 1635-1641, Oct. 1997.

[2] Narain G. Hingorani, Laszlo Gyugyi, "Understanding FACTS: Concepts and Technology of Flexible AC Transmission Systems", IEEE Press, 2000.

[3] Mohan Ned, "Power Electronics: applications and desing", Wiley, 1995.

[4] Cardenas V, Moran L, Bahamondes A, Dixon J, " Comparative analysis of real time reference generation techniques for four-wire shunt active power filters", presented at the 34th annual Power Electronics Specialist Conference (PESC), pp. 791-796, June 2003.

[5] H. Akagi, A. Nabae, "The pq Theory in three phase systems under nonlinear conditions ", ETEP, vol. 3, N 1, pp. 27-31, Jan/Feb. 1993.

[6] K. Masoud, M. Reza, "A Non-linear Adaptative Filter for Online Signal Analysis in Power Systems: Aplications ", IEEE Trans. Power Delivery,vol. 17, $\mathrm{N}^{\circ}$ 2, pp. 617-622, April 2002.

[7] Jose H. Vivas, Member,IEEE, and Julie D. Zambrano, Student Member, IEEE Control of Thyristor Controlled Series Capacitor Based on Instantaneous Power Theory. 